\title{
A study on the effect of knowledge management on customer orientation in governmental organization
}

\author{
Asadollah Kordnaeij $^{\mathbf{a}^{*}}$, Saeed Dehyadegari ${ }^{\mathrm{b}}$ and Alireza Bakhshizadeh ${ }^{\mathrm{c}}$
}

\author{
${ }^{a}$ Associate Professor in Management and Economics, Tabriat Modares University, Tehran, Iran \\ ${ }^{b}$ Shahid Bahoner University of Kerman, Kerman, Iran \\ ${ }^{c}$ Master student in Faculty of Management and Economics, Tabriat Modares University, Tehran, Iran \\ AR T I C LE I N F O
}

Article history:

Received April 17, 2012

Accepted 11 June 2012

Available online

June 122012

Keywords:

Knowledge Management

Customer orientation

Customer retention

Customer absorption

Customer relationship

management

\section{Introduction}

Business orientation has been widely used to revolve around a company's products and services, there are several influencing factors in product, and service-oriented business included proper functioning and pricing (Anderson \& Kerr, 2002). Customer orientation (CoP) normally involves a group of necessary actions taken by a firm to help its sales and service staff in considering client requirements and satisfying most their priorities. Business strategies normally reflect a customer orientation can include different items such as developing a quality product appreciate by consumers; responding properly and respectfully to consumer complaints and queries; and dealing sensitively with community issues. Elliott (2000) summarized the CoP concepts and requirements, described some evaluation results and proposed the way ahead.

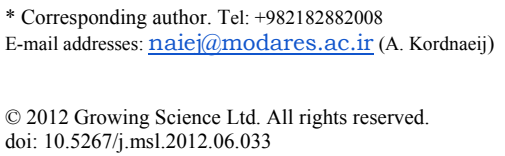


Pelled et al. (2000) investigated the relationship between two constructs studied independently from each other including organizational demography and prosocial organizational behavior (POB). They developed a conceptual framework, which proposes how these constructs are correlated. The proposed framework considered two hypotheses. In the first one, they examined whether diversity variables high in job-relatedness and low in visibility are positively associated with customer-oriented POB. In the second hypothesis, they attempted to find out whether diversity variables low in jobrelatedness and high in visibility are negatively associated with such POB. Their preliminary test results provided some support for both hypotheses.

Alptekin and Bener (2010) proposed a framework for an architecture where unutilized bands were relicensed to various service providers on a short-term basis. The proposed framework concentrated on the resource allocation process of these leased bands to customers and they claimed that it could be utilized as a decision support tool to satisfy the quality of service requirements of individual users and achieve a reliable utilization of network resources. The hypothesis was that customer information yields an efficient customer-oriented resource management strategy and the allocation process integrates the necessary data about the customer demographics and usage behavior. They did a simulation and the results seemed to prove that the population size of a customer group was not always an indicator for higher revenue for a service provider.

Many CoP problems often formulated in a more sophisticated mathematical model and they are solved using recent advances of optimization techniques. Mahdavi et al. (2011), for instance presented an alternative problem formulation for the catalog segmentation problem and they used a metaheuristics approach to solve the resulted problem. The proposed model includes clever features to avoid getting trapped in a local optimum. The results of an extensive computational study using real and synthetic data sets demonstrated the performance of the algorithm.

Kang and Hyun (2012) performed an investigation to detect the optimal facets of communication style for customer-oriented service employees and to investigate the ways in which the customeroriented service employee (COSE) induces luxury restaurant patrons' dedicational attitudes. The results of their survey analysis disclosed that five types of communication styles including attentive, friendly, impression leaving, open, and relaxed bear a positive effect on COSE, while one communication style (contentious) bears a negative effect. They also reported that the customeroriented service employee plays an important role in inducing three types of dedicational behaviors in consumers, which includes enhancement, cooperation, and advocacy.

Knowledge management (KM), on the other hand, plays an important role on promoting customer orientation (Nonaka \& Konno, 1998; Earl \& Scott, 1999). KM can be defined as different strategies and processes built to identify, capture, structure, value, leverage, and share a firm's intellectual assets to incorporate its performance and competitiveness. Lee and Chen (2012) built an intellectual structure by investigating a total of 10,974 publications in KM field from 1995 to 2010. They applied document co-citation analysis, pathfinder network and strategic diagram techniques to provide a dynamic view of the evolution of KM research trends. Their study provided a systematic and objective tool in exploring the development of the KM discipline. The results of this study revealed that the coverage of key KM papers had expanded into a broad spectrum of disciplines. Liang et al. (2012) applied a fuzzy quality function deployment to prioritize KM solutions for an international port in Taiwan. They concluded that 'establishment of a data storage and data mining system' in the technology dimension was the most urgent need for KM implementation at port K in Taiwan.

The proposed study of this paper presents an empirical study to find the relationship between KM and $\mathrm{CoP}$ in governmental organizations. The proposed study of this paper first presents details of the proposed study in section 2, section 3 presents the findings of our survey and finally concluding remarks are given in the last to summarize the contribution of the paper. 


\section{The proposed study}

The proposed study of this paper looks for an appropriate answer for three questions: whether there is a significant relationship between KM and attracting more customers, whether there is a significant relationship between $\mathrm{KM}$ and retention and customer loyalty, and finally, whether there is a significant relationship between KM and customer relationship. Fig. 1 shows the framework of the proposed study.

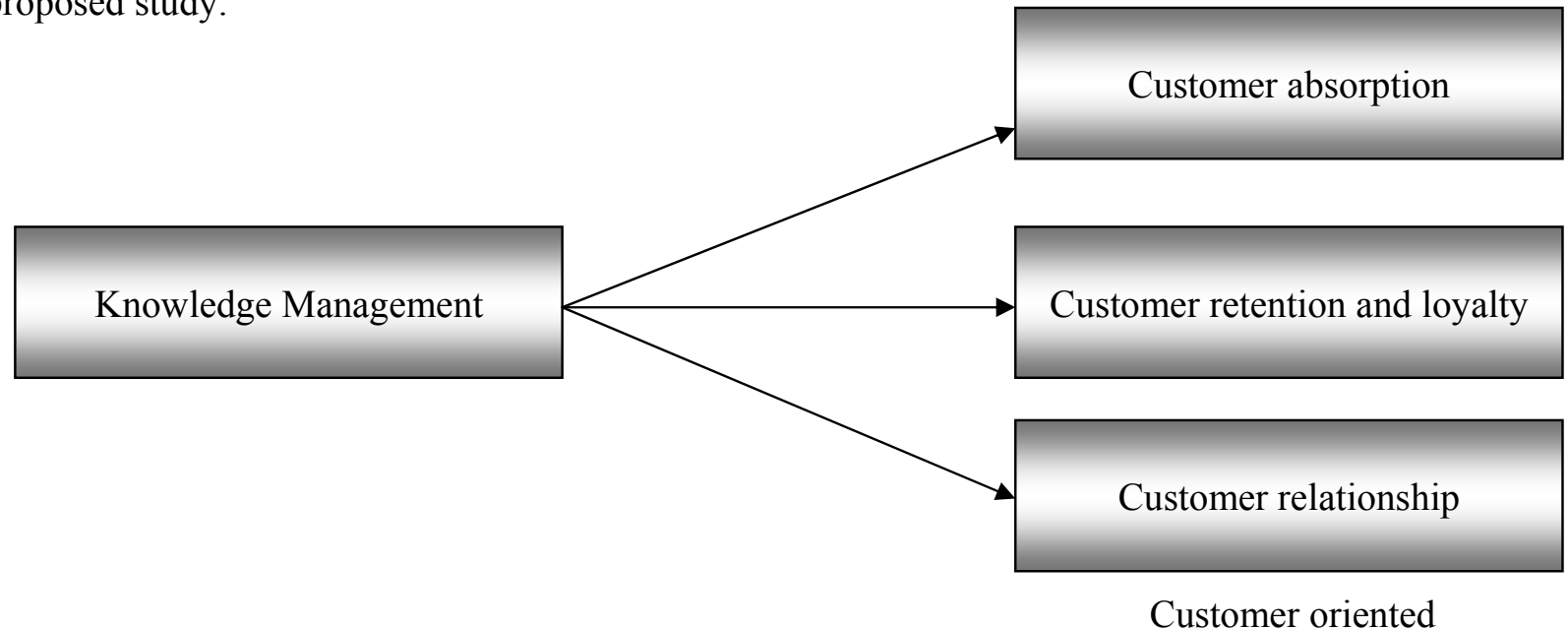

Fig. 1. The proposed framework of the study

The study of this research is descriptive correlation and causal and effect. The goal of study is an applied research and it is a descriptive correlation study. We use questionnaire to collect the necessary data and we have consulted many top managers to discuss all the related issues. The study was held in one of Iranian city named Chahbahar located in south east of the country and we have selected the sample from four organizations of water resources management, Free Zone, customs agencies and traffic management.

We use the following formula to calculate the minimum number of sample size,

$n=\frac{N \times z_{\alpha / 2}^{2} \times p \times q}{\varepsilon^{2} \times(N-1)+z_{\alpha / 2}^{2} \times p \times q}$,

where $N$ is the population size, $p=1-q$ represents the yes/no categories, $z_{\alpha / 2}$ is CDF of normal distribution and finally $\varepsilon$ is the error term. Since we have $p=0.5, z_{\alpha / 2}=1.96$ and $N=170$, the number of sample size is calculated as $n=146$.

There were 170 people working in these organizations and using Kokran sampling technique, we chose 146 people and distributed the questionnaires. In other words, we chose 34 out of 40 employee who worked for water resources management, 28 people out of 30 people who worked for Free Zone, 66 people out of 80 people who worked for custom and 18 people out of 20 people who worked for traffic organization.

\subsection{Validity and reliability of measurement tools}

We have used Cronbach's alpha test to verify the reliability of the survey questionnaire and to test its validity using confirmatory factor analysis. Cronbach alpha for knowledge management, customer absorption, customer retention and loyalty and customer relationship management were $0.96,0.841$, 0.88 and 0.91 , respectively and an overall Cronbach alpha was 0.906. As we see, Cronbach's alpha values of all variables are greater than 0.7 , which validates our results. On the other hand, all load 
factors were greater than 0.5 and based on the results we can conclude that the questionnaire has good reliability and validity. Table 1 shows the results of correlation among four components of the survey.

Table 1

The results of correlation test

\begin{tabular}{lllll}
\hline & $\begin{array}{l}\text { Knowledge } \\
\text { management }\end{array}$ & $\begin{array}{l}\text { Customer } \\
\text { absorption }\end{array}$ & $\begin{array}{l}\text { Customer } \\
\text { retention }\end{array}$ & $\begin{array}{l}\text { Customer relationship } \\
\text { management }\end{array}$ \\
\hline Knowledge management & 1 & & & \\
\hline Customer absorption & 0.43 & 1 & 1 & 1 \\
\hline Customer retention & 0.87 & 0.63 & 0.54 & \\
\hline $\begin{array}{l}\text { Customer relationship } \\
\text { management }\end{array}$ & 0.67 & 0.72 & & \\
\hline
\end{tabular}

Based on the results of Table 1, there is strong correlation between KM and customer retention and also between customer relationship management and customer absorption. The other components also represent positive relationships.

\section{The results}

The proposed study of this paper uses structural equation model to analyze the proposed model. Fig. 2 shows details of our results. In Fig. 2, ABS represents customer absorption, Retention represents customer retention, CRM denotes customer relationship management and finally KM represents knowledge management.

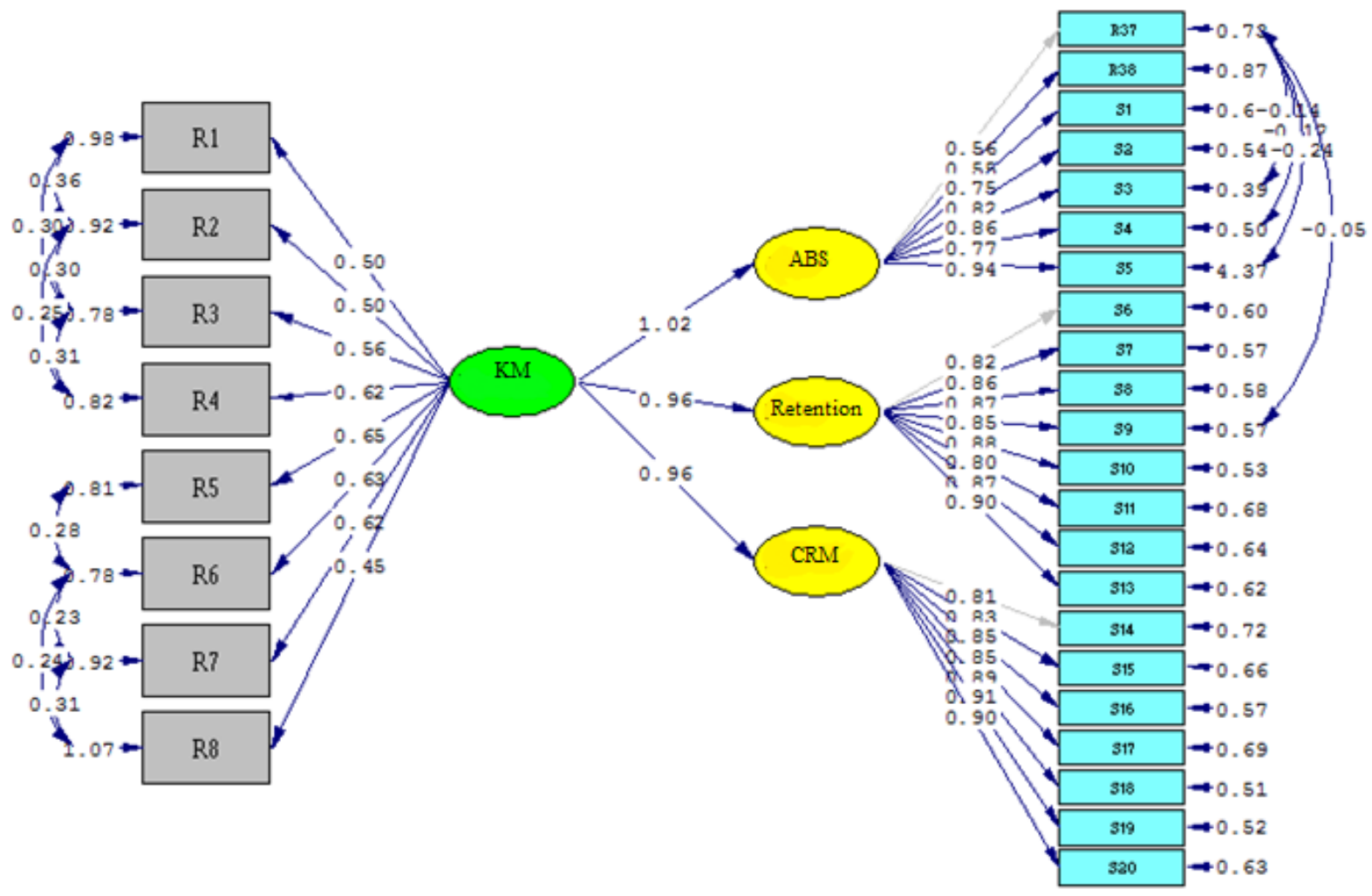

Fig. 2. The proposed SEQ model

Table 2 shows summary of our findings based on the implementation of SEQ mode. 
Table 2

The summary of the implementation of SEM to test three sub-hypotheses and one main hypothesis

\begin{tabular}{lllll}
\hline Hypothesis & t-student & $\beta$ & $\mathrm{r}^{2}$ & Result \\
\hline The effects of KM on customer absorption & 14.66 & 1.02 & & Confirmed \\
The effects of KM on customer retention & 13.01 & 0.96 & 0.89 & Confirmed \\
The effects of KM on customer relationship management & 16.44 & 0.96 & & Confirmed \\
Main hypothesis: The effects of KM on CoP & 13.60 & 0.98 & 0.78 & Confirmed \\
\hline
\end{tabular}

As we see, all null hypotheses have been confirmed when the level of significance is 0.01 , the main hypothesis of this paper also has been approved bringing us to a conclusion that KM has positive impact on $\mathrm{CoP}$.

The first sub-hypothesis is associated with the relationship between KM and customer absorption and as we can observe t-student is meaningful when the level of significance is 0.01 . Based on the result, we can conclude that as an increase on KM efforts will lead us to have the same increase on customer absorption. This positive conclusion holds for the effects of KM on customer retention when the level of significance is one percent and we can conclude that as KM increases by one percent, we can expect an increase of 0.96 percent on customer retention. Similarly, we can conclude that an increase of one percent on KM will yield 0.96 percent increase on customer relationship management. Overall, the goodness of the fitness of the proposed model is about $78 \%$, which means an increase of one percent on KM will increase of 0.98 on $\mathrm{CoP}$.

Note that knowledge management is not just storing and retrieving the information but we wish to interpret and use the necessary information and this could happen only by having a good culture within the organization. Using KM with an adaption of information technology can increase productivity and integrity of individuals within the organization. Knowledge management is a conscious process of creating knowledge, it helps validate the knowledge and distributed it with its applications. If an organization attempts to use $\mathrm{KM}$, there must be a balance between people and technology.

\section{Conclusion}

In this paper, we have presented an empirical study to investigate the effects of KM on customer orientation. The proposed study of this paper considered three sub hypothesis including whether KM has positive impact on customer absorption, customer retention and customer relationship management. The proposed study of this paper used a standard questionnaire and using structural equation modeling selected a sample of study from the four groups of employees who worked for different governmental organization in Iran. The results of our study revealed that there were positive and meaningful relationships between $\mathrm{KM}$ and three mentioned variables as well as CoP. In summary, we have concluded that an increase of one percent on KM could result to an increase of approximately the same amount in customer absorption, retention and customer relationship management.

\section{Acknowledgment}

The authors would like to thank the employees of different governmental organizations who kindly help us finish this survey.

\section{References}

Alptekin, G.I., \& Bener, A.B. (2010). Customer oriented resource allocation framework in cognitive radio. Computers \& Industrial Engineering, 58(3), 401-410.

Anderson, K. \& Kerr, C. (2002). Customer Relationship Management. New York, McGraw Hill. 
Earl, M.J., \& Scott, I.A. (1999). Opinion: What is a Chief Knowledge Officer. MIT Sloan Management Review, Cambridge, MA, 40(2), 29-38.

Elliott, J.J. (2000). Design of a product-focused customer-oriented process. Information and Software Technology, 42(14), Pages 973-981.

Lee, M.R., Chen, T.T. (2012). Revealing research themes and trends in knowledge management: From 1995 to 2010. Knowledge-Based Systems, 28, 47-58.

Liang, G.S., Ding, J.F., Wang, C.K. (2012). Applying fuzzy quality function deployment to prioritize solutions of knowledge management for an international port in Taiwan. Knowledge-Based Systems, 33, 83-91.

Kang, J., \& Hyun, S.S. (2012). Effective communication styles for the customer-oriented service employee: Inducing dedicational behaviors in luxury restaurant patrons. International Journal of Hospitality Management, 31(3), 772-785.

Mahdavi, I., Movahednejad, M., \& Adbesh, F. (2011). Designing customer-oriented catalogs in eCRM using an effective self-adaptive genetic algorithm. Expert Systems with Applications, 38(1), 631-639.

Nonaka I., \& Konno N. (1998). The concept of 'ba': building a foundation for knowledge creation. California Management Review, 40 (3), 40-54.

Pelled, L.H., Cummings, T.G., \& Kizilos, M.A. (2000). The Influence of Organizational Demography on Customer-Oriented Prosocial Behavior: An Exploratory Investigation. Journal of Business Research, 47(3), 209-216 